\title{
Relay Dual Catalysis: Photoredox and NHC-Catalyzed Cross-Double C-H Functionalizations of Aldehydes and Alkenes
}

Ming-Shang Liu ${ }^{\dagger}$, Lin $\mathrm{Min}^{\dagger}$, Bi-Hong Chen ${ }^{\dagger}$, and Wei Shu ${ }^{\dagger, *}$

†Shenzhen Grubbs Institute, Department of Chemistry, and Guangdong Provincial Key Laboratory of Catalysis, Southern University of Science and Technology, Shenzhen 518055, Guangdong, P. R. China.

*E-mail: shuw@sustech.edu.cn

\begin{abstract}
Direct functionalizations of two distinct inert C-H bonds represent the most ideal ways to construct $\mathrm{C}-\mathrm{C}$ bonds. Herein, we report an intermolecular vinylation of aldehydes using alkenes as the vinylating reagents through sequential two-fold $\mathrm{C}-\mathrm{H}$ functionalizations. The merging of visible light and NHC-catalysis allows for the direct coupling of alkenes with aldehydes through an unprecedented relay dual catalysis enabled cross-dehydrogenative coupling mechanism. The use of diphenoquinone is essential for the success of this reaction, which plays an intriguing two-fold role in the reaction, as both an electron acceptor as well as a radical reservoir for the radical coupling enabling $\mathrm{C}-\mathrm{C}$ forming-process.
\end{abstract}

$\mathrm{C}-\mathrm{C}$ bonds represent one of the most ubiquitous and important chemical bonds in nature. ${ }^{1}$ Thus, the development of efficient construction of $\mathrm{C}-\mathrm{C}$ bonds has been a longterm interest and challenge in synthetic chemistry and related areas. ${ }^{2}$ Conventional cross-coupling reactions between $\mathrm{C}-\mathrm{X} / \mathrm{C}-\mathrm{X}$ and $\mathrm{C}-\mathrm{H} / \mathrm{C}-\mathrm{X}$, where $\mathrm{X}=$ (pseudo)-halides or metals, to form $\mathrm{C}-\mathrm{C}$ bonds rely heavily on pre-installation of activated chemical handles for starting materials. ${ }^{3}$ Although these re-actions are highly synthetic useful, the pre-activation of substrates requires additional steps to prepare, and generation of stoichiometric amount of metal salts as byproducts. For this reason, crossdehydrogenative coupling (CDC) represents an ideal alternative for $\mathrm{C}-\mathrm{C}$ bond formation from two distinct $\mathrm{C}-\mathrm{H}$ bonds. ${ }^{4}$ The significant features of $\mathrm{CDC}$ reactions include: (1) no pre-functionalization of substrates is required, demonstrating step- and atom-economy with reduced wastes, (2) direct $\mathrm{C}-\mathrm{H}$ functionalizations are highly valuable for late-stage functionalizations (Scheme 1a). ${ }^{5}$

On the other hand, N-heterocyclic carbene (NHC) catalysis ${ }^{6}$ and visible light catalysis $^{7}$ have emerged as powerful tools for organic synthesis over the past decades. ${ }^{8}$ To this end, to develop visible-light and NHC-catalysis enabled CDC reactions are 1 
attractive but challenging. Rovis reported the $\alpha$-acylation of tertiary amines enabled by the visible-light and NHC-catalyzed cross-dehydrogenative coupling of aldehydes with $\alpha$-position of amines via ionic pathways (Scheme $1 \mathrm{~b}$ ). ${ }^{9,10}$ The visible-light and NHCcatalyzed cross-dehydrogenative coupling enabled by radical-radical coupling via single electron pathways remains underdeveloped (Scheme 1c).

Over the past years, significant advances in NHC-catalyzed single electron transfer (SET) reactions have been achieved. ${ }^{11}$ This radical mechanism offers a new opportunity of realizing NHC-mediated cross-coupling reactions to form $\mathrm{C}-\mathrm{C}$ or $\mathrm{C}-\mathrm{X}$ bonds. ${ }^{12}$ Ohmiya, and Li groups reported elegant examples of NHC-catalyzed radical decarboxylative coupling of aldehydes with alkenes in the presence of redox-active esters or activated alkyl halides. ${ }^{13}$ In these processes, a carbon electrophile (R-X species) couples with Breslow intermediates from aldehydes to form $\mathrm{C}-\mathrm{C}$ bond via a radical mechanism. ${ }^{14}$ To date, no report on the dehydrogenative $\mathrm{C}-\mathrm{C}$ coupling of aldehydes with alkenes is successful. Additionally, extending the CDC partner to simple and "light" substrates like alkenes $\left(\mathrm{C}_{s p 2}-\mathrm{H}\right)$ would be highly valuable. ${ }^{5}$ Herein, we report the first visible-light and NHC-catalyzed cross-dehydrogenative $\mathrm{C}-\mathrm{C}$ bond-forming process from aldehydes and alkenes enabled by a radical relay catalysis (Scheme 1c). The use of visible-light and NHC-catalysis strategy allows for the direct dehydrogenative vinylation of aldehydes with alkenes at room temperature via an unprecedented relay catalysis pathway, representing the first CDC reaction of alkenes. The oxidant plays a dual role as a single electron acceptor as well as an intriguing radical reservoir in the reaction.

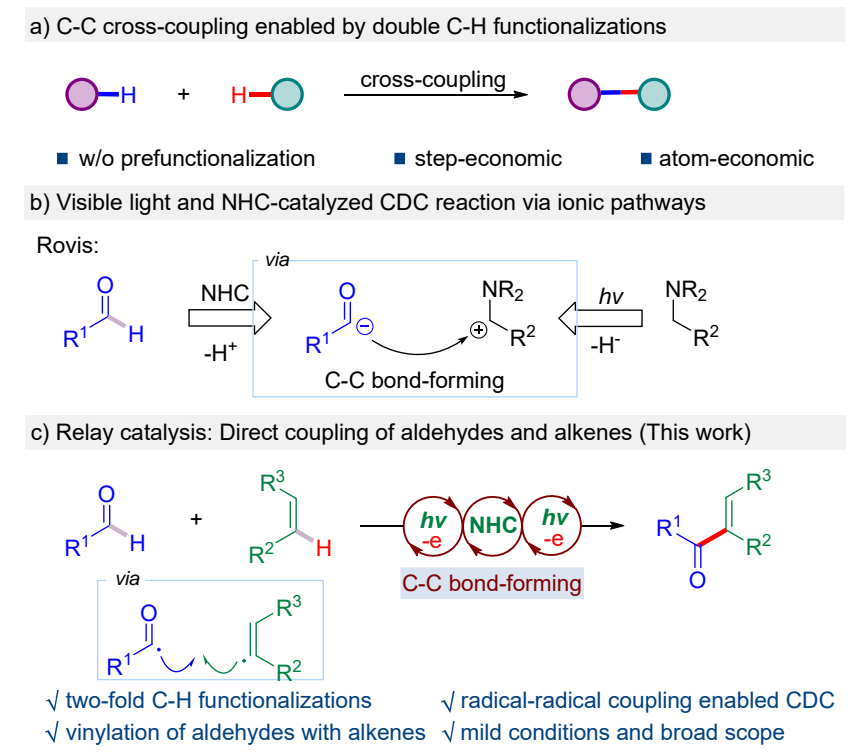

Scheme 1. Impetus for Radical Relay Catalysis Enabled Two-fold C-H Functionalizations 
We started to investigate the reaction using 4-methylbenzaldehyde $\mathbf{1 a}$ and 4methoxystyrene $\mathbf{2 a}$ as the prototype substrates. After extensive optimization of the reaction parameters, we define the use of $\mathrm{Ru}(\mathrm{bpy}){ }_{3} \mathrm{Cl}_{2} \cdot 6 \mathrm{H}_{2} \mathrm{O}(2 \mathrm{~mol} \%)$ and NHC-1 (10 mol\%) as catalyst, potassium carbonate (1.0 equiv) as base, sodium benzenesulfinate (1.9 equiv) as additive, TTBDPB (3,3',5,5'-tetra-tert-butyldiphenoquinone, 1.9 equiv) as oxidant in DMSO $(0.1 \mathrm{M})$ under irradiation of $30 \mathrm{~W}$ blue LED at room temperature as the optimal conditions. The cross-dehydrogenative coupling between 1a and $2 \mathrm{a}$ afforded the desired vinylaryl ketone 3a in $81 \%$ isolated yield (Table 1 and Tables S1S8). ${ }^{15}$ The use of other NHC (N-heteroatom carbene) catalyst could also mediate the transformation, albeit in lower conversions and yields (Table 1, entries 2 and 3 and Table S2). Other photocatalysts with reasonable oxidative potential proved efficient for this reaction (Table 1, entries 4-6 and Table S3). Replacing potassium carbonate with other bases resulted in lower yields of $\mathbf{3 a}$ (Table S4). TTBDPB proved essential for the success of this two-fold C-H functionalization reaction. The use of 1,4-benzoquinone, DDQ, or potassium persulfate as oxidant led to low efficiency of this reaction (Table 1, entries 7-9, and Table S6). Many other sulfinate derivatives could also mediate the reaction (Table S7). Among which, sodium benzenesulfinate furnished the best result of 3a. Control experiments revealed that both the NHC catalyst and photocatalyst were essential for the desired transformation (Table 1, entries 10 and 11). No light irradiation led to no formation of 3a (Table 1, entry 12), proving the use of visible light is critical to the success of this transformation. No 3a was detected in the absence of oxidant (Table 1, entry 13).

Table 1. Reaction Development ${ }^{a}$

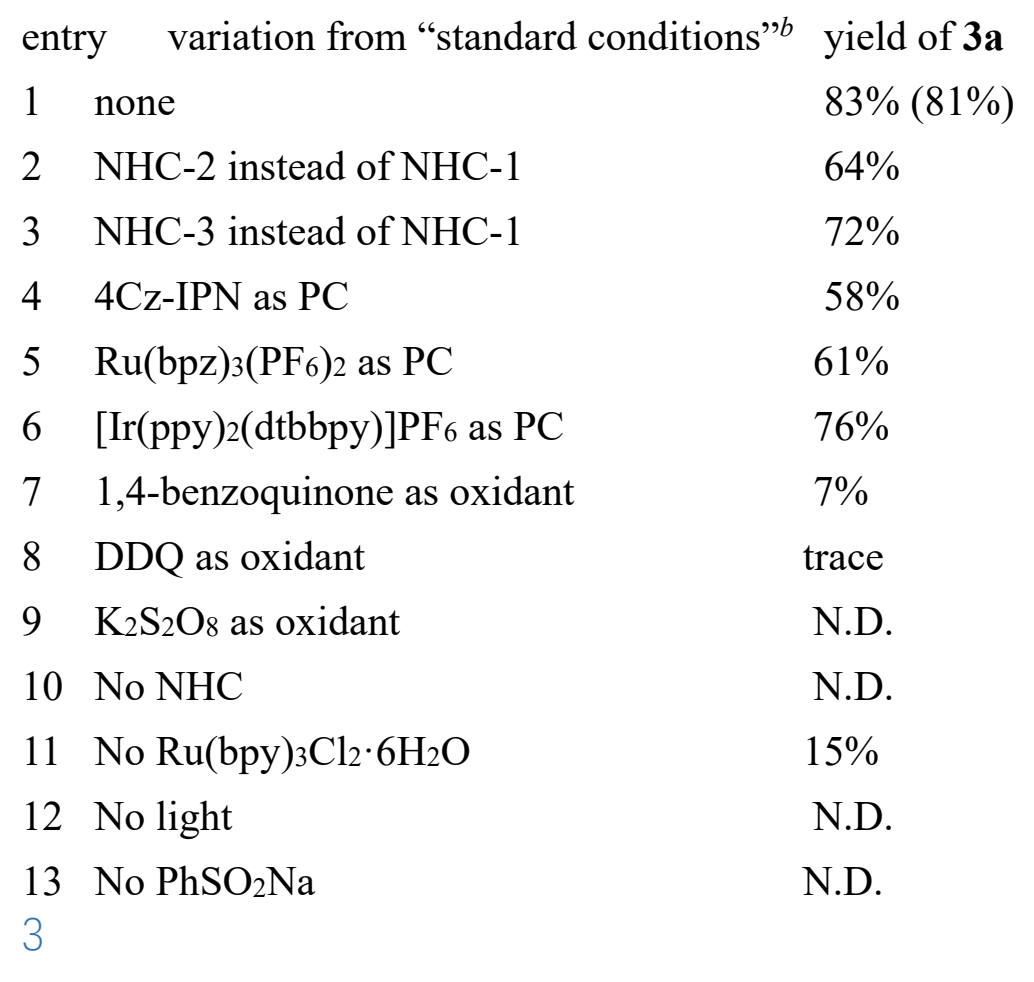


${ }^{a}$ The reaction was conducted using $\mathbf{1 a}(0.2 \mathrm{mmol}), \mathbf{2 a}(0.1 \mathrm{mmol})$ with $30 \mathrm{~W}$ blue LEDs under indicated conditions. ${ }^{b}$ Yield was determined by ${ }^{1} \mathrm{H}$ NMR of the crude mixture of the reaction using mesitylene as internal standard. Number in the parenthesis is the yield after flash chromatography. PC = photocatalyst. N.D. = not detected.

With the optimized conditions in hand, we turned to evaluate the scope of this reaction. The mild conditions tolerated a wide variety of functional groups and substitution patterns in terms of both aldehydes and alkenes for this dual-catalyzed CDC reaction (Scheme 2). First, the scope of aldehydes was examined. Electronwithdrawing and electron-donating substituted aromatic aldehydes were well tolerated under the reaction conditions, giving the corresponding vinylketones in 50-86\% yields (3b-3q). Various para-substituted aromatic aldehydes were all good subtrates for this reaction, affording the desired C-C coupling products in 50-86\% yields (3b-3j). Notably, fluoro-, chloro-, bromo-, and iodo-substituted aldehydes were successfully transformed into the desired products in 50\%-72\% yields (3f-3i), leaving a chemical handle for further elaboration. meta-Substituted aromatic aldehyde could be converted to the desired product $\mathbf{3 k}$ in $82 \%$ yield. Naphthyl aldehyde could be coupled with 2a to give the desired product 31 in $65 \%$ yield. ortho-Substituted aldehyde could be tolerated to give the desired product $\mathbf{3 m}$ in $69 \%$ yield. Moreover, the reaction was compatible with highly functionalized aldehydes. Various sensitive functional groups, such as amides with free N-H, alkenes, alkynes were well tolerated under the reaction conditions, delivering the two-fold C-H functionalization products in $66-84 \%$ yields (3n-3p). The structure of the products was unambiguously assigned by the X-ray diffraction analysis of 3n. Furthermore, heteroaromatic aldehydes containing triazoles, pyridines, quinolines, furans, benzathiophenes, thiophenes were all good substrates for this transformation, affording corresponding vinyl heteroaryl ketones in 56-92\% yields (3q3w). Next, the scope of alkenes was tested. Aromatic alkenes with para-substituents, such as thioethers, halides, and esters, could be converted to the desired vinylketones in $52-85 \%$ yields $(\mathbf{4 a - 4 i})$. The practicality of this reaction was showcased by the gramscale synthesis of $\mathbf{4 c}$ without erasing the efficiency of this reaction. Under the standard conditions, $5.0 \mathrm{mmol}$ of 4-tert-butylstyrene was successfully coupled with $\mathbf{1 a}$ to afford 1.04 gram of vinylarylketone $4 \mathbf{c}$ in $75 \%$ yield. Alkenes with meta- and orthosubstituents could be converted to the desired ketones in $65-79 \%$ yield (4j-4l). Multisubstituted aromatic alkenes were successfully involved in the reaction, giving the desired acylated product $\mathbf{4 m}$ in $81 \%$ yield. Fused aromatic alkene was converted to $\mathbf{4 n}$ in $86 \%$ yield. Moreover, alkenes bearing alkynes, amides were good substrates for the reaction, furnishing acylated alkenes in 50-78\% yields (4o-4q). Notably, heteroaryl 
Table 2. Scope for the Double C-H Functionalization Reaction with Respect to Aldehydes and Alkenes. ${ }^{a}$

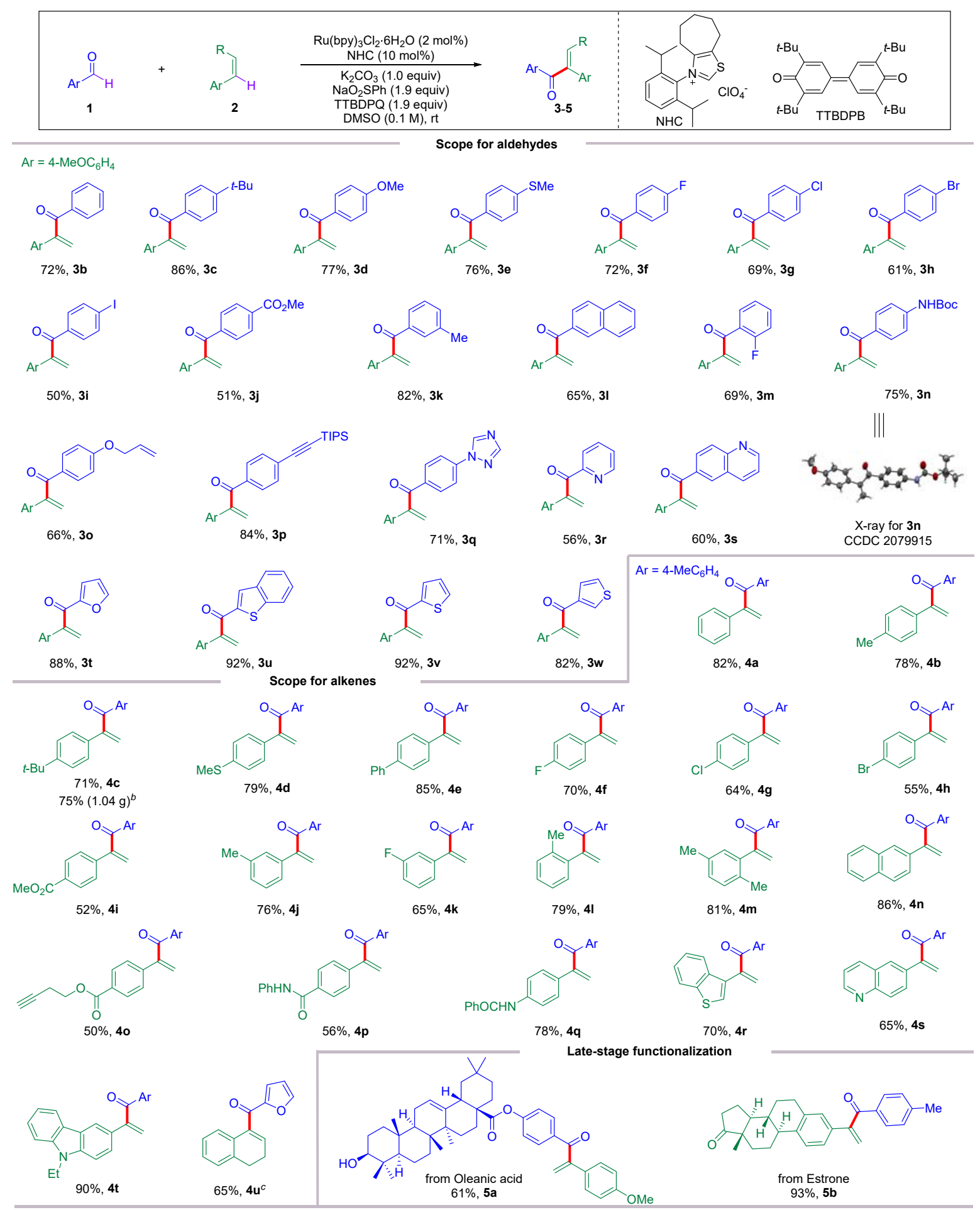

${ }^{a}$ Standard conditions, see Table 1 for detail. ${ }^{b}$ The reaction was conducted on $5.0 \mathrm{mmol}$ scale.

alkenes, such as benzothiophene, quinoline, carbazole containing alkenes proceeded smoothly to give corresponding heteroaryl vinyl ketones in $65-90 \%$ yields $(4 \mathbf{r}-\mathbf{4 t})$. 5 
Internal alkenes could undergo regio selective acylation with aldehydes to give corresponding arylvinyl ketone $\mathbf{4 u}$ in $65 \%$ yield. To further demonstrate the synthetic potential of this mild protocol, the reaction was applied to late-stage functionalization of natural products. Oleanic acid derived aldehyde and estrone derived alkene were both successfully involved into this two-fold $\mathrm{C}-\mathrm{H}$ functionalization process to deliver corresponding vinylarylketones (5a and $\mathbf{5 b}$ ) in $61 \%$ and $93 \%$ yields, respectively.
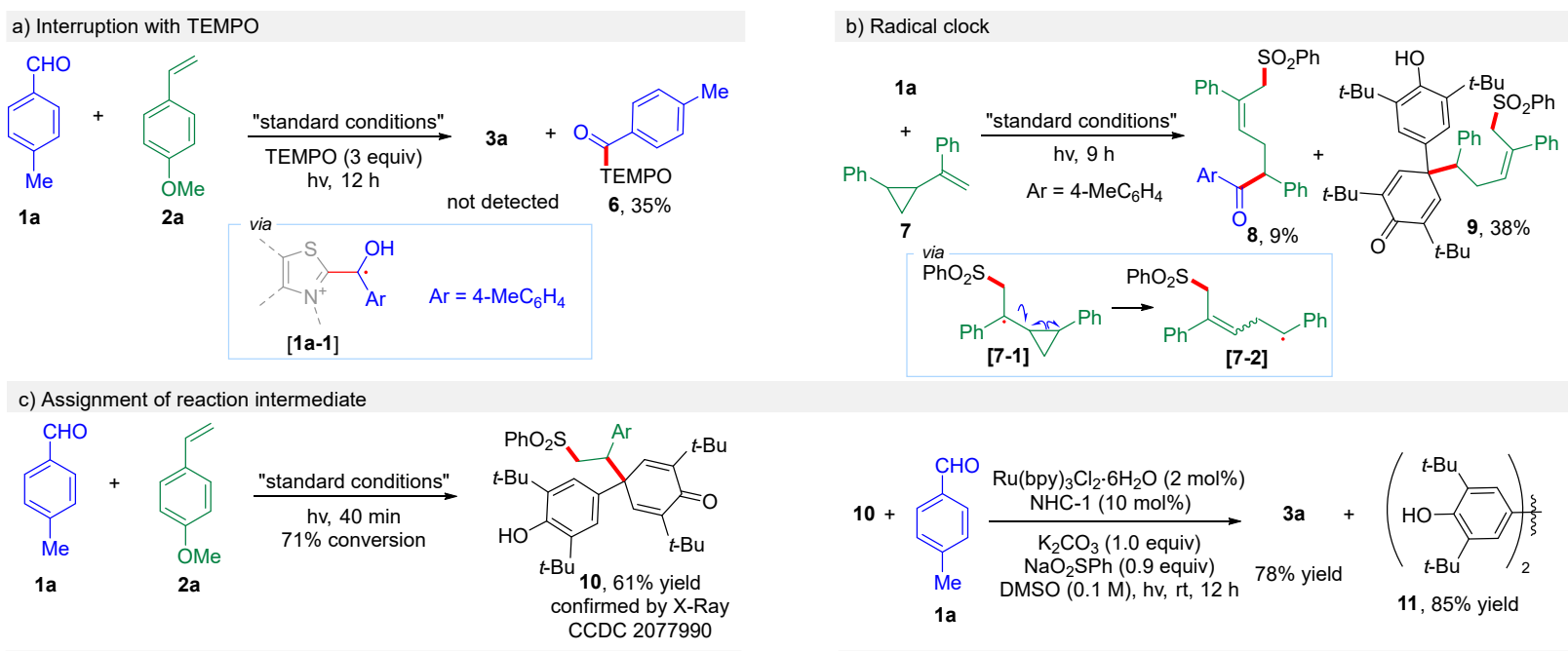

d) Light on-off experiments

e) Luminescence quenching experiments
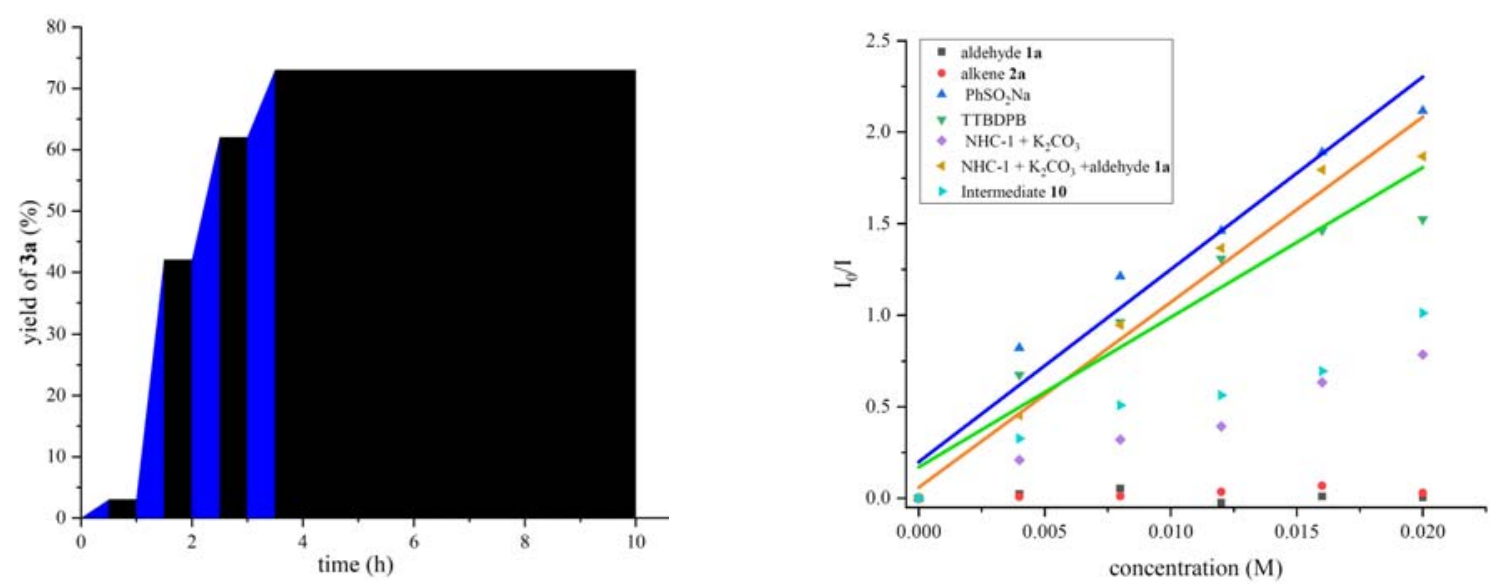

Scheme 2. Control Experiments and Mechanistic Investigations of the Reaction.

To shed light on the mechanism of this reaction, we set up a series of experiments to probe the reaction pathway (Scheme 2). First, radical scavenger TEMPO was added to the reaction of aldehyde 1a with alkene $\mathbf{2 a}$ under otherwise identical to standard conditions (Scheme 2a). C-C coupling product 3a from desired double C-H functionalization process was complete shutdown. Instead, the adduct $\mathbf{6}$ from the addition of TEMPO with 1a was obtained in 35\% yield, indicating the involvement of C-centered radical [1a-1] originating from the single electron oxidation of Breslow intermediate of aldehyde with NHC catalyst. Second, the reaction of aldehyde 1a with cyclopropyl styrene 7 was carried out under standard conditions. Ring-opening of 6 
cyclopropane was observed, with the formation of $\mathbf{8}$ in $9 \%$ yield and $\mathbf{9}$ in $38 \%$ yield (Scheme $2 b$ ). This result suggested the reaction proceeded via the radical intermediate [7-1], followed by radical ring-opening of cyclopropane to give radical intermediate [72]. Third, the reaction of aldehyde $1 \mathbf{a}$ with alkene $\mathbf{2 a}$ under standard conditions was conducted for $40 \mathrm{~min}$. Intriguingly, the adduct $\mathbf{1 0}$ was formed in $61 \%$ yield from the addition of phenylsulfinate with quinone and alkene $\mathbf{2 a}$ (Scheme 2c). The structure of $\mathbf{1 0}$ was further determined by the X-ray diffraction analysis. Further submission of $\mathbf{1 0}$ to the reaction with $\mathbf{1 a}$ in the presence of sodium benzenesulfinate ( 0.9 equiv) under otherwise identical to standard conditions delivered the vinylation of alkene 3a in $78 \%$ yield along with the formation of biphenol 11 in 85\% yield (Scheme 2c). These results indicated the adduct $\mathbf{1 0}$ is the intermediate of this dual $\mathrm{C}-\mathrm{H}$ bond functionalization process of aldehydes and alkenes, serving as the reservoir of alkyl radicals for C-C bond-forming with aldehydes. Next, light on-off experiment was carried out with aldehyde 1a and alkene $\mathbf{2 s}$ (Scheme 2d). The light on-off results indicated the reaction underwent a catalytic radical reaction instead of a radical chain pathway. ${ }^{16}$ Then luminescence quenching experiments were examined with different components (Scheme 2e). ${ }^{7 \text { a }}$ None of aldehyde 1a, alkene 2a, the mixture of NHC-1 catalyst with potassium carbonate, or intermediate $\mathbf{1 0}$ showed significant luminescence quenching effect to the excited state of photocatalyst $\left(\mathrm{Ru}(\mathrm{II})^{*}\right)$. On the contrast, soudium benzenesulfinate as well as the combination of aldehyde 1a with NHC-1 in the presence of potassium carbonate showed very strong quenching effect to the excited photocatalyst. These observations provided evidence that either sodium benzenesulfinate or the combination of aldehyde 1a with NHC-1 and potassium carbonate could quench $\mathrm{Ru}(\mathrm{II})^{*}$ to give $\mathrm{Ru}(\mathrm{I})$ species via single electron transfer. Moreover, the monitor of the profile for the reaction of aldehyde 1a and alkene $\mathbf{2 a}$ under standard conditions was conducted. The results in Figure 1 showed that alkene 2a was quickly consumed in the first 40 minutes of the reaction with little formation of coupling product 3a. Instead, the yield of $\mathbf{1 0}$ increased dramatically. After 40 minutes, yield of 3a started to increase with the consumption of 10. Finally, 3a was formed in $78 \%$ yield with full conversion of $\mathbf{1 0}$ in $4 \mathrm{~h}$. These results strongly suggested that this double $\mathrm{C}-\mathrm{H}$ cross-functionalization of aldehydes with alkenes proceeded stepwisely via a relay process of photoredox and NHC-catalysis, proving that $\mathbf{1 0}$ as the intermediate of this reaction. 


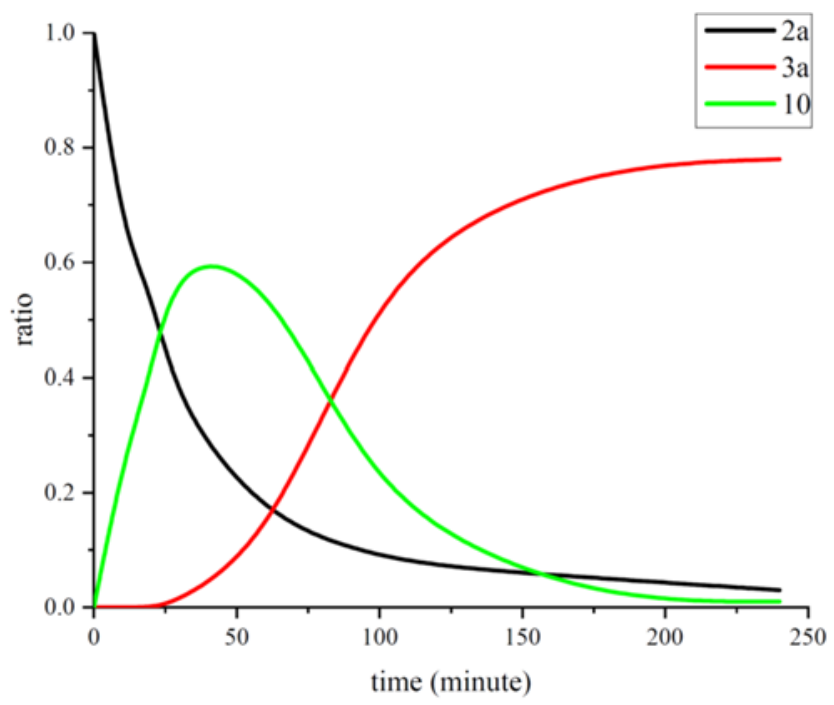

Figure 1. Reaction profile of the reaction of $1 \mathbf{a}$ with $\mathbf{2 a}$.

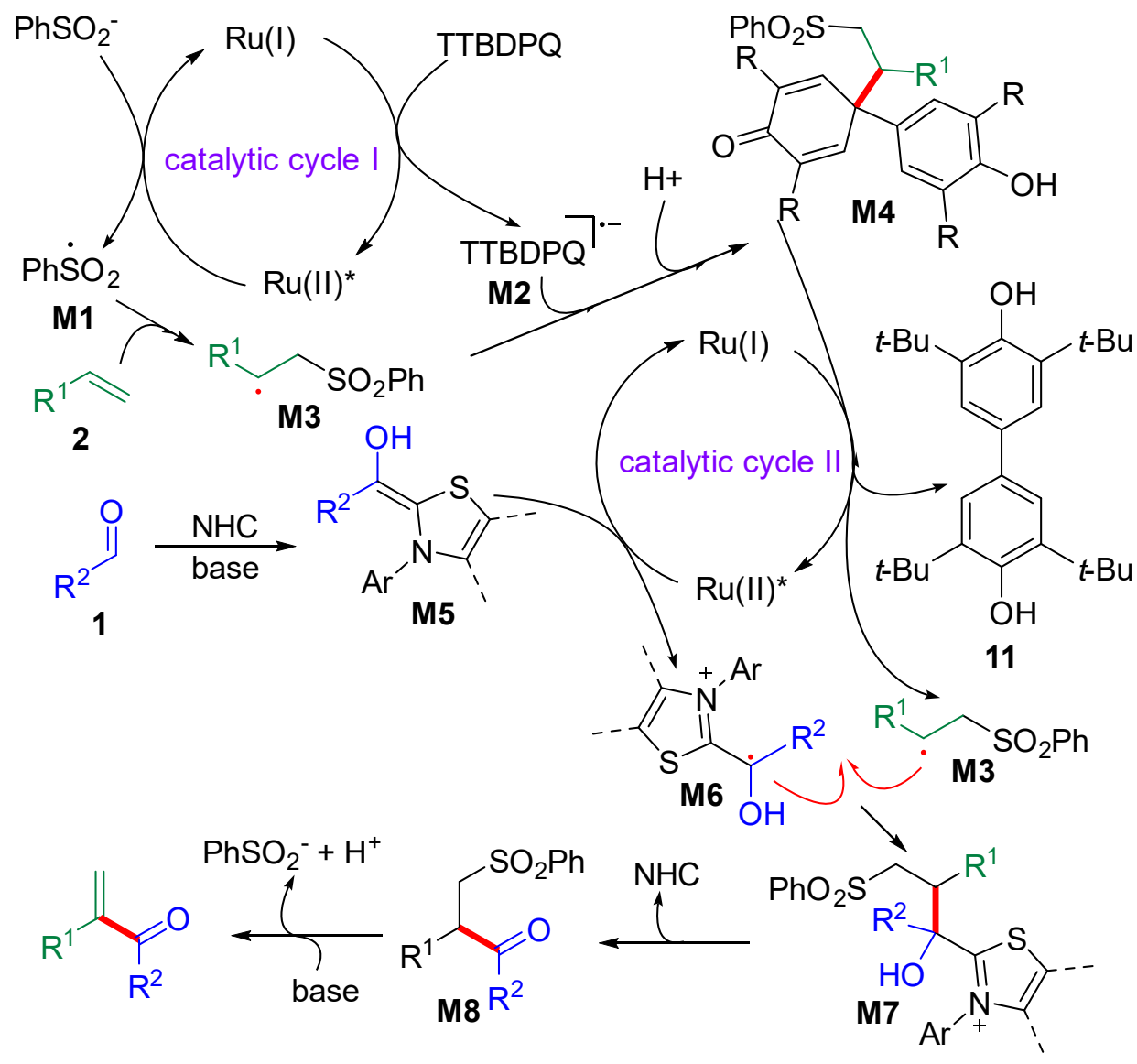

Scheme 3. Proposed Mechanism of the Reaction.

Based on the above-mentioned mechanistic results and literature, the plausible mechanism for this transformation is depicted in Scheme 3. First, $\mathrm{Ru}(\mathrm{II})^{*}$ was formed via photo-excitation of $\mathrm{Ru}(\mathrm{II})$-based photocatalyst, which was quenched by phenylsulfinate to give $\mathrm{Ru}(\mathrm{I})$ species as well as phenyl sulfonyl radical $\mathrm{M} 1$. $\mathrm{Ru}(\mathrm{II})$ could be regenerated by single electron oxidation of oxidant (TTBDBQ) with the 
formation of radical anion intermediate M2. In the presence of alkene, M1 would undergo radical addition to alkene to give carbon centered radical M3, which rebounded with $\mathbf{M} 2$ via radical-radical coupling followed by protonation to give M4. Aldehyde 1 condensed with nitrogen heterocyclic carbene catalyst (NHC) to generate corresponding Breslow intermediate M5 with the assistance of base, ${ }^{17}$ which could quench the excited photocatalyst $\left(\mathrm{Ru}(\mathrm{II})^{*}\right)$ by single electron transfer to form radical cationic intermediate $\mathbf{M 6}$ and $\mathrm{Ru}(\mathrm{I})$ species. ${ }^{18}$ The reduced photocatalyst $\mathrm{Ru}(\mathrm{I})$ coud reduce $\mathbf{M} 4$ to regenerate radical intermediate $\mathbf{M 3}$ and $\mathrm{Ru}$ (II) by single electron transfer. Intermediates M3 and M6 would undergo radical-radical cross-coupling to deliver M7 via $\mathrm{C}-\mathrm{C}$ bond-forming. Upon releasing the NHC catalyst, $\mathbf{M} 7$ could be transformed to M8. In the presence of a proper base, final product was formed by elimination of phenylsulfinate. $^{12 \mathrm{c}, 19}$

In summary, a vinylation of aldehydes using alkenes at room temperature has been demonstrated for the first time. The reaction was enabled by visible-light and NHCcatalyzed site- and regioselective cross-dehydrogenation coupling of aldehydes and alkenes. Mechanistic investigations reveal the reaction features a novel two-cycle relay dual catalysis pathway to realize the sequential two-fold $\mathrm{C}-\mathrm{H}$ cross-functionalizations. Diphenoquinone plays an unprecedented two-fold role in the reaction, acting as an oxidant and a reservoir for alkyl radical intermediates. The reaction tolerates a wide range of aldehydes and alkenes with good functional group compatibility. We anticipate the relay catalysis will open an avenue for visible-light and NHC-catalyzed carboncarbon and carbon-heteroatom bond-forming processes.

\section{ACKNOWLEDGMENT}

We sincerely thank NSFC (21971101 and 21801126), Guangdong Basic and Applied Basic Research Foundation (2019A1515011976), The Pearl River Talent Recruitment Program (2019QN01Y261), Thousand Talents Program for Young Scholars, Guangdong Provincial Key Laboratory of Catalysis (No. 2020B121201002) for financial support. We acknowledge the assistance of SUSTech Core Research Facilities. We thank Dr. Xiaoyong Chang (SUSTech) for X-ray crystallographic analysis of $\mathbf{3 n}$ (CCDC 2079915) and 10 (CCDC 2077990) and Dr. Yi-Dan Du (SUSTech) and Si-Fan $\mathrm{Li}$ (SUSTech) for reproducing the results of $\mathbf{3 h}, \mathbf{4 a}, \mathbf{5 h}$ and $\mathbf{6 b}$.

\section{REFERENCES}

(1) Perry, I. B.; Brewer, T. F.; Sarver, P. J.; Schultz, D. M.; DiRocco, D. A.; MacMillan, D. W. C. Direct arylation of strong aliphatic $\mathrm{C}-\mathrm{H}$ bonds. Nature 2018, 560, 70-75.

(2) Jana, R.; Pathak, T. P.; Sigman, M. S. Advances in Transition Metal (Pd, Ni, Fe)Catalyzed Cross-Coupling Reactions Using Alkyl-organometallics as Reaction Partners. 
Chem. Rev. 2011, 111, 1417-1492.

(3) Metal Catalyzed Cross-Coupling Reactions, 2nd ed.; De Meijere, A., Diederich, F., Eds.; Wiley-VCH: Weinheim, Germany, 2004.

(4) (a) Li, C.-J. Cross-Dehydrogenative Coupling (CDC): Exploring $\mathrm{C}-\mathrm{C}$ Bond Formations beyond Functional Group Transformations. Acc. Chem. Res. 2009, 42, $335-$ 344. (b) Girard, S. A.; Knauber, T.; Li, C.-J. The Cross-Dehydrogenative Coupling of

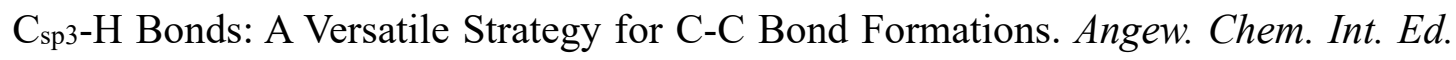
2014, 53, 74-100. (c) Li, C.-J. Exploration of New Chemical Reactivities for Sustainable Molecular Transformations. Chem 2016, 1, 423-437. (d) Gulzar, N.; Schweitzer-Chaput, B.; Klussmann, M. Oxidative coupling reactions for the functionalization of C-H bonds using oxygen. Catal. Sci. Technol. 2014, 4, 2778-2796. (e) Varun, B. V.; Dhineshkumar, J.; Bettadapur, K. R.; Siddaraju, Y.; Alagiri, K.; Prabhu, $\mathrm{K}$. R. Recent advancements in dehydrogenative cross coupling reactions for $\mathrm{C}-\mathrm{C}$ bond formation. Tetrahedron Lett. 2017, 58, 803-824.

(5) Huang, C.-Y.; Kang, H.; Li, J.; Li, C.-J. En Route to Intermolecular CrossDehydrogenative Coupling Reactions. J. Org. Chem. 2019, 84, 12705-12721.

(6) For selected reviews, see: (a) Enders, D.; Niemeier, O.; Henseler, A. Organocatalysis by N-Heterocyclic Carbenes. Chem. Rev. 2007, 107, 5606-5655. (b) Bugaut, X.; Glorius, F. Organocatalytic Umpolung: N-Heterocyclic Carbenes and Beyond. Chem. Soc. Rev. 2012, 41, 3511-3522 (c) Hopkinson, M. N.; Richter, C.; Schedler, M.; Glorius, F. An Overview of N-Heterocyclic Carbenes. Nature 2014, 510 , 485-496. (d) Flanigan, D. M.; Romanov-Michailidis, F.; White, N. A.; Rovis, T. Organocatalytic Reactions Enabled by N-Heterocyclic Carbenes. Chem. Rev. 2015, 115, 9307-9387. (e) Levin, E.; Ivry, E.; Diesendruck, C. E.; Lemcoff, N. G. Water in NHeterocyclic Carbene-Assisted Catalysis. Chem. Rev. 2015, 115, 4607-4692. (f) Chen, X.; Wang, H.; Jin, Z.; Chi, Y. R. N-Heterocyclic Carbene Organocatalysis: Activation Modes and Typical Reactive Intermediates. Chin. J. Chem. 2020, 38, 1167-1202. (g) Ishii, T.; Nagao, K.; Ohmiya, H. Recent Advances in N-Heterocyclic Carbene-Based Radical Catalysis. Chem. Sci. 2020, 11, 5630-5636.

(7) For selected reviews, see: (a) Prier, C. K.; Rankic, D. A.; MacMillan, D. W. Visible Light Photoredox Catalysis with Transition Metal Complexes: Applications in Organic Synthesis. Chem. Rev. 2013, 113, 5322-5363. (b) Ravelli, D.; Protti, S.; Fagnoni, M. Carbon-Carbon Bond Forming Reactions via Photogenerated Intermediates. Chem. Rev. 2016, 116, 9850-9913. (c) Romero, N. A.; Nicewicz, D. A. Organic Photoredox Catalysis. Chem. Rev. 2016, 116, 10075-10166. (d) Skubi, K. L.; Blum, T. R.; Yoon, T. P. Dual Catalysis Strategies in Photochemical Synthesis. Chem. Rev. 2016, 116, 10035-10074. (e) Wang, C. S.; Dixneuf, P. H.; Soule, J. F. Photoredox 
Catalysis for Building C-C Bonds from C(sp²)-H Bonds. Chem. Rev. 2018, 118, 75327585. (f) Yu, X. Y.; Chen, J. R.; Xiao, W. J. Visible Light-Driven Radical-Mediated CC Bond Cleavage/Functionalization in Organic Synthesis. Chem. Rev. 2021, 121, 506561.

(8) For reviews on the merging of photoredox and NHC-catalysis, see: (a) Hopkinson, M. N.; Sahoo, B.; Li, J.-L.; Glorius, F. Dual Catalysis sees the Light: Combining Photoredox with Organo-, Acid and Transition Metal Catalysis. Chem. Eur. J. 2014, 20, 3874-3886. (c) Liu, J.; Xing, X.-N.; Huang, J.-H.; Lu, L.-Q.; Xiao, W.-J. Light Opens a New Window for N-Heterocyclic Carbene Catalysis. Chem. Sci. 2020, 11, $10605-$ 10613. (d) Liu, M.-S.; Shu, W. Catalytic, Metal-Free Amide Synthesis from Aldehydes and Imines Enabled by a Dual-Catalyzed Umpolung Strategy under Redox-Neutral Conditions. ACS Catal. 2020, 10, 12960-12966.

(9) DiRocco, D. A.; Rovis, T. Catalytic Asymmetric $\alpha$-Acylation of Tertiary Amines Mediated by a Dual Catalysis Mode: N-Heterocyclic Carbene and Photoredox Catalysis. J. Am. Chem. Soc. 2012, 134, 8094-8097.

(10) (a) Gao, Z.-H.; Xia, Z.-H.; Dai, L.; Ye, S. N-Heterocyclic Carbene Catalyzed Photooxidation: Intramolecular Cross Dehydrogenative Coupling of Tetrahydroisoquinoline-Tethered Aldehydes. Adv. Synth. Catal. 2020, 362, 1819-1824. (b) Jiang, D.; Wu, Z.; Wang, J. NHC-Catalyzed Redox-Neutral Aza-Benzoin Reaction of Aldehydes with Tetrahydroisoquinolines. Chin. J. Chem. 2020, 38, 135-138

(11) (a) Yang, W.; Hu, W.; Dong, X.; Li, X.; Sun, J. N-Heterocyclic Carbene Catalyzed $\gamma$-Dihalomethylenation of Enals by Single-Electron Transfer. Angew. Chem. Int. Ed. 2016, 55, 15783-15786. (b) Dai, L.; Xia, Z. H.; Gao, Y. Y.; Gao, Z. H.; Ye, S. Visible-Light-Driven N-Heterocyclic Carbene Catalyzed $\gamma$ - and $\varepsilon$-Alkylation with Alkyl Radicals. Angew. Chem. Int. Ed. 2019, 58, 18124-18130. (c) Mavroskoufis, A.; Rajes, K.; Golz, P.; Agrawal, A.; Russ, V.; Gotze, J. P.; Hopkinson, M. N. NHeterocyclic Carbene Catalyzed Photoenolization/Diels-Alder Reaction of Acid Fluorides. Angew. Chem. Int. Ed. 2020, 59, 3190-3194. (d) Dai, L.; Ye, S. Photo/NHeterocyclic Carbene Co-Catalyzed Ring Opening and $\gamma$-Alkylation of Cyclopropane Enal. Org. Lett. 2020, 22, 986-990.

(12) (a) Rehbein, J.; Ruser, S. M.; Phan, J. NHC-Catalysed Benzoin CondensationIs It All Down to the Breslow Intermediate? Chem. Sci. 2015, 6, 6013-6018. (b) Regnier, V.; Romero, E. A.; Molton, F.; Jazzar, R.; Bertrand, G.; Martin, D. What Are the Radical Intermediates in Oxidative N-Heterocyclic Carbene Organocatalysis? J. Am. Chem. Soc. 2019, 141, 1109-1117. (c) Liu, K.; Studer, A. Direct $\alpha$-Acylation of Alkenes via NHeterocyclic Carbene, Sulfinate, and Photoredox Cooperative Triple Catalysis. J. Am. Chem. Soc. 2021, 143, 4903-4909. (d) Meng, Q.-Y.; Lezius, L.; Studer, A. Benzylic 
C-H Acylation by Cooperative NHC and Photoredox Catalysis. Nat. Commun. 2021, $12,2068$.

(13) (a) Ishii, T.; Kakeno, Y.; Nagao, K.; Ohmiya, H. N-Heterocyclic CarbeneCatalyzed Decarboxylative Alkylation of Aldehydes. J. Am. Chem. Soc. 2019, 141, 3854-3858. (b) Ishii, T.; Ota, K.; Nagao, K.; Ohmiya, H. N-Heterocyclic CarbeneCatalyzed Radical Relay Enabling Vicinal Alkylacylation of Alkenes. J. Am. Chem. Soc. 2019, 141, 14073-14077. (c) Kakeno, Y.; Kusakabe, M.; Nagao, K.; Ohmiya, H. Direct Synthesis of Dialkyl Ketones from Aliphatic Aldehydes through Radical NHeterocyclic Carbene Catalysis. ACS Catal. 2020, 10, 8524-8529. (d) Ota, K.; Nagao, K.; Ohmiya, H. N-Heterocyclic Carbene-Catalyzed Radical Relay Enabling Synthesis of $\delta$-Ketocarbonyls. Org. Lett. 2020, 22, 3922-3925. (d) Ohmiya, H. N-Heterocyclic Carbene-Based Catalysis Enabling Cross-Coupling Reactions. ACS Catal. 2020, 10, 6862-6869. (e) Li, J.-L.; Liu, Y.-Q.; Zou, W.-L.; Zeng, R.; Zhang, X.; Liu, Y.; Han, B.; He, Y.; Leng, H.-J.; Li, Q.-Z. Radical Acylfluoroalkylation of Olefins through NHeterocyclic Carbene Organocatalysis. Angew. Chem. Int. Ed. 2020, 59, 1863-1870. (f) Gao, Y.; Quan, Y.; Li, Z.; Gao, L.; Zhang, Z.; Zou, X.; Yan, R.; Qu, Y.; Guo, K. Organocatalytic Three-Component 1,2-Cyanoalkylacylation of Alkenes via Radical Relay. Org. Lett. 2021, 23, 183-189.

(14) (a) Davies, A. V.; Fitzpatrick, K. P.; Betori, R. C.; Scheidt, K. A. Combined Photoredox and Carbene Catalysis for the Synthesis of Ketones from Carboxylic Acids. Angew. Chem. Int. Ed. 2020, 59, 9143-9148. (b) Meng, Q. Y.; Doben, N.; Studer, A. Cooperative NHC and Photoredox Catalysis for the Synthesis of $\beta$-Trifluoromethylated Alkyl Aryl Ketones. Angew. Chem. Int. Ed. 2020, 59, 19956-19960.

(15) For more details on the conditions optimization, please see Supporting Information.

(16) (a) Miyake, Y.; Nakajima, K.; Nishibayashi, Y. Visible-Light-Mediated Utilization of $\alpha$-Aminoalkyl Radicals: Addition to Electron-Deficient Alkenes Using Photoredox Catalysts. J. Am. Chem. Soc. 2012, 134, 3338-3341. (b) Liu, Q.; Yi, H.; Liu, J.; Yang, Y.; Zhang, X.; Zeng, Z.; Lei, A. Visible-Light Photocatalytic Radical Alkenylation of $\alpha$-Carbonyl Alkyl Bromides and Benzyl Bromides. Chem. Eur. J. 2013, 19, 5120-5126. (c) Huang, H.; Zhang, G.; Gong, L.; Zhang, S.; Chen, Y. Visible-LightInduced Chemoselective Deboronative Alkynylation under Biomolecule-Compatible Conditions. J. Am. Chem. Soc. 2014, 136, 2280-2283. (d) Cismesia, M. A.; Yoon, T. P. Characterizing Chain Processes in Visible Light Photoredox Catalysis. Chem. Sci. 2015, 6, 5426-5434.

(17) (a) Breslow, R. Rapid Deuterium Exchange in Thiazolium Salts. J. Am. Chem. Soc. 1957, 79, 1762-1763. (b) Breslow, R. On the Mechanism of Thiamine Action. IV. ${ }^{1}$ 
Evidence from Studies on Model Systems. J. Am. Chem. Soc. 1958, 80, 3719-3726. (c) Paul, M.; Neudorfl, J. M.; Berkessel, A. Breslow Intermediates from a Thiazolin-2ylidene and Fluorinated Aldehydes: XRD and Solution-Phase NMR Spectroscopic Characterization. Angew. Chem. Int. Ed. 2019, 58, 10596-10600.

(18) Speckmeier, E.; Fischer, T. G.; Zeitler, K. A Toolbox Approach to Construct Broadly Applicable Metal-Free Catalysts for Photoredox Chemistry: Deliberate Tuning of Redox Potentials and Importance of Halogens in Donor-Acceptor Cyanoarenes. $J$. Am. Chem. Soc. 2018, 140, 15353-15365.

(19) Zhu, S.; Qin, J.; Wang, F.; Li, H.; Chu, L. Photoredox-Catalyzed BranchSelective Pyridylation of Alkenes for the Expedient Synthesis of Triprolidine. Nat. Commun. 2019, 10, 749. 